\title{
Pharmacokinetics and Monte Carlo Dosing Simulations of Imipenem in Critically III Patients with Life-Threatening Severe Infections During Support with Extracorporeal Membrane Oxygenation
}

\author{
Sutep Jaruratanasirikul ${ }^{1}$ (D) - Veerapong Vattanavanit ${ }^{1} \cdot$ Wibul Wongpoowarak $^{2} \cdot$ Monchana Nawakitrangsan $^{1}$. \\ Maseetoh Samaeng ${ }^{1}$
}

Published online: 4 September 2020

(c) Springer Nature Switzerland AG 2020

\begin{abstract}
Background Extracorporeal membrane oxygenation (ECMO), a cardiopulmonary bypass device, has been found to increase the profound pathophysiological changes associated with life-threatening severe infections in patients with multiple comorbidities, which results in alterations of pharmacokinetic patterns for antibiotics.

Objectives The aims of this study were (1) to determine the pharmacokinetics of imipenem and (2) to assess the probability of target attainment (PTA) for imipenem in critically ill patients with life-threatening severe infections during support with ECMO. Methods The pharmacokinetic studies were carried out following administration of $0.5 \mathrm{~g}$ of imipenem every $6 \mathrm{~h}$ on the 4 th dose of drug administration in 10 patients and a Monte Carlo simulation was performed to determine the PTA of achieving $40 \%$ exposure time during which the plasma drug concentrations remained above minimum inhibitory concentration $\left(T>_{\text {MIC }}\right)$ and $80 \% T>_{\text {MIC. }}$

Results The median values of volume of distribution and total clearance (CL) of imipenem in these patients were $13.98 \mathrm{~L}$ and $9.78 \mathrm{~L} / \mathrm{h}$, respectively. A high PTA ( $\geq 90 \%$ ) for a target of $80 \%$ with a MIC of $4 \mu \mathrm{g} / \mathrm{mL}$ in patients with $\mathrm{CL}_{\mathrm{CR}} 60-120 \mathrm{~mL} / \mathrm{min}$ and flow rate of ECMO circuit 3-5.5 L/min was observed when imipenem was administered by a 4-h infusion of $1 \mathrm{~g}$ every $6 \mathrm{~h}$. Conclusions A high dosage regimen such as $1 \mathrm{~g}$ every $6 \mathrm{~h}$ of imipenem may be required to achieve pharmacodynamic targets against less susceptible pathogens in this patient population.
\end{abstract}

ClinicalTrial.gov Identifier NCT03776305, date of registration: 11 December 2018.

\section{Introduction}

Extracorporeal membrane oxygenation (ECMO), a cardiopulmonary bypass device, provides temporary cardiorespiratory support for patients with severe respiratory and/or cardiac failure refractory to conventional therapy $[1,2]$. This device was previously used primarily for lifesaving support in pediatric patients; however, in the past decade, it has been

Electronic supplementary material The online version of this article (https://doi.org/10.1007/s13318-020-00643-3) contains supplementary material, which is available to authorized users.

Sutep Jaruratanasirikul

jasutep@medicine.psu.ac.th

1 Division of Internal Medicine, Faculty of Medicine, Prince of Songkla University, Hat Yai 90110, Songkla, Thailand

2 Department of Pharmaceutical Technology, Faculty of Pharmaceutical Sciences, Prince of Songkla University, Hat Yai 90110, Songkla, Thailand increasingly used for both respiratory and cardiac failure in adult patients [1-3]. The severity of multiple comorbidities in critically ill patients and life-threatening severe infections as well as the impact of the ECMO circuit itself have been shown to enhance the profound pathophysiological changes associated with these critical conditions, leading to alterations in the pharmacokinetics of several therapeutic drugs, including increased volume of distribution $(V)$ and decreased total clearance (CL) of concomitant antimicrobial agents used in the treatment of severe infections [1-4]. However, studies on the impact of ECMO on the pharmacokinetics of antimicrobial agents have usually been conducted in pediatric populations, resulting in difficulties extrapolating the data for use in adult populations due to significant differences in absorption, distribution, metabolism and excretion of the therapeutic drugs between these two populations [1-3].

Imipenem, a drug in the carbapenem class, is a $\beta$-lactam antimicrobial agent with a broad spectrum of activity against Gram-negative bacilli, Gram-positive cocci, and anaerobic 


\section{Key Points}

ECMO has been found to increase the profound pathophysiological changes associated with life-threatening severe infections in patients with multiple comorbidities, which results in alterations of pharmacokinetic patterns and the achievement of pharmacodynamic targets for antimicrobial therapy.

High dosage regimens of imipenem are required for coverage of less susceptible pathogens for achieving the maximal pharmacodynamic targets and therapeutic outcomes in this patient population.

bacteria. This agent is commonly prescribed for the treatment of highly resistant pathogens causing life-threatening severe nosocomial infections [5,6]. A previous study in critically ill patients with ventilator-associated pneumonia for assessment of pharmacokinetic changes during imipenem therapy found that the median values of $V$ and CL were 30.3 $\mathrm{L}$ and $13.2 \mathrm{~L} / \mathrm{h}$, respectively, which were greater than the values obtained from healthy volunteers $[7,8]$. In tropical countries, the stability of the carbapenem class of antibiotics is a crucial consideration when continuous or prolonged infusion is to be used in patients on ECMO. A previous study found that imipenem, the drug with the greatest instability among the $\beta$-lactams, remained $90 \%$ stable for $3 \mathrm{~h}$ and 30 min at $25{ }^{\circ} \mathrm{C}$ but became degraded by up to $25 \%$ within $24 \mathrm{~h}$ at that temperature [9]. Dosage recommendations for imipenem for the treatment of severe infections in critically ill patients during support with ECMO have not been determined to date. Therefore, the aims of this study were (1) to determine the pharmacokinetics of imipenem and (2) to assess the probability of target attainment (PTA) for imipenem in critically ill patients with life-threatening severe infections during support with ECMO.

\section{Patients and Methods}

\subsection{Study Population and Design}

The study was conducted in critically ill patients with respiratory and/or cardiac failure and severe infections admitted to the Intensive Care Unit (ICU) of Songklanagarind Hospital, the largest tertiary care center in southern Thailand, between December 2015 and February 2019. All patients aged $\geq 18$ years who had cardiopulmonary failure and were supported by ECMO and received a 1-h infusion of $0.5 \mathrm{~g}$ of imipenem/cilastatin diluted in $100 \mathrm{~mL}$ of normal saline solution, delivered via infusion pump at a constant flow rate, every $6 \mathrm{~h}$ for the treatment of severe infections for 14 days were included. The protocol for the study was approved by the Ethics Committee of Songklanagarind Hospital, and written informed consent was obtained from each subject's legally acceptable representative before enrollment.

\subsection{Drugs and Chemicals}

Imipenem/cilastatin $\left(\right.$ Tienam $\left.^{\circledR}\right)$ was purchased from MSD, Thailand. Imipenem standard powder was purchased from the US Pharmacopeia (Rockville, MD, USA) as pure powder. All the solvents were of high-performance liquid chromatography (HPLC) grade.

\subsection{Blood Sampling}

The imipenem pharmacokinetic studies were carried out during administration of the fourth dose of imipenem (18-24 h after the start of the regimen) in the ICU with the air conditioning at an average temperature of $25^{\circ} \mathrm{C}$. Blood samples $(\sim 3 \mathrm{~mL})$ were obtained via a heparinized intravascular catheter (on the side of the body opposite that used for administration of the study drug) by direct venipuncture at the following times-before (time zero) and at 0.25 , $0.5,0.75,1,2,3,4,5$ and $6 \mathrm{~h}$ after the fourth dose of each regimen. The blood samples were added to a heparinized tube and centrifuged at $1000 \mathrm{~g}$ for $10 \mathrm{~min}$ not later than $15 \mathrm{~min}$ after collection. An equal volume of stabilizing solution (0.5 M MOPS/water/ethylene glycol, 2:1:1, v/v/v) was added to each plasma sample [8], which was then vortexed and stored at $-80{ }^{\circ} \mathrm{C}$ until analysis within 1 week.

\subsection{Imipenem Assay}

The concentrations of imipenem (not for cilastatin concentrations) were determined by reversed-phase HPLC. The samples were prepared by the method of Garcia-Capdevila et al. [10]. Briefly, $250 \mu \mathrm{L}$ of the stabilizing solution was added to $250 \mu \mathrm{L}$ of the sample. The mixture was then subjected to ultrafiltration, using an Ultrafree ${ }^{\circledR}-\mathrm{MC}$ Centrifugal Filter Unit, for $10 \mathrm{~min}$ at $6000 \mathrm{~g}$. An aliquot of the sample $(50 \mu \mathrm{L})$ was injected onto a Nova-Pak C18 column (Waters Associates, Milford, MA, USA). The mobile phase used $0.2 \mathrm{M}$ borate buffer ( $\mathrm{pH} 7.2)$ at a flow rate of $1 \mathrm{~mL} / \mathrm{min}$. The column effluent was monitored by a photodiode array detector (Waters 2996; Waters Associates) at $300 \mathrm{~nm}$. The validation tests were found to be within acceptable limits as per the 2013 US Food and Drug Administration Guidance on Bioanalytical Method Validation [11]. The lower limit of quantitation (LLOQ) of imipenem was $0.25 \mu \mathrm{g} / \mathrm{mL}$. This assay was found to be selective as no interference was found with a biological matrix on six individual blank plasma. The intraassay reproducibility values characterized by coefficients of 
variation (CVs) were $0.19 \%, 0.71 \%$ and $0.11 \%$ for samples containing $0.75,20$ and $75 \mu \mathrm{g} / \mathrm{mL}$, respectively. The interassay reproducibility precision values, calculated by $\mathrm{CVs}$, were $0.39 \%, 1.63 \%$ and $0.23 \%$ for samples containing 0.75 , 20 and $75 \mu \mathrm{g} / \mathrm{mL}$, respectively. A short-term stability study showed that at room temperature, the concentrations of imipenem losses for samples containing 0.75 and $75 \mu \mathrm{g} / \mathrm{mL}$ were $<1 \%$ for at least $1 \mathrm{~h}$. A long-term stability study showed that at $-80{ }^{\circ} \mathrm{C}$, the concentrations of imipenem losses for samples containing 0.75 and $75 \mu \mathrm{g} / \mathrm{mL}$ were $<5 \%$ for at least 14 days. Carryover testing was performed, but no carryovers were found.

\subsection{Pharmacokinetic Analysis}

From a visual plot of the concentration-time profile, it was obvious that a one-compartment model was not suitable for describing the observed concentrations. We used a twocompartment model for three reasons. First, data sampling was too sparse for a three-compartment model. Second, previous earlier studies supported a two-compartment model [12-15]. Third, in order to analyze covariates in a clinical setting, the total pharmacokinetic parameters and other clinical parameters should be much lower than the number of subjects in the study. Therefore, the two-compartment model was the most appropriate model to use in this study. The Taylor series expansion method was used for solving the differential equations describing the two-compartment infusion model by using an in-house Visual Basic programming language in a Microsoft Excel spread sheet (Microsoft Corp., Redmond, WA, USA). Pharmacokinetic parameters were obtained by non-linear regression to minimize the objective function (obj) of the sum square errors (SSEs):

$o b j=\min \left(\sum_{i=1}^{N}\left(\ln y_{\text {actual }}-\ln y_{\text {calc }}\right)_{i}^{2}\right)$

where $y_{\text {actual }}$ and $y_{\text {calc }}$ are the observed and calculated concentrations, respectively, for all $\mathrm{N}$ data points. The SSEs of the objective function were used to describe the quality of fit. Since the aim of a pharmacokinetic/pharmacodynamic simulation is to determine the time above the minimum inhibitory concentration (MIC), the elimination phase behavior is critical for reliable prediction near the MIC. With this calculation, a logarithmic scale is used to describe observed concentrations instead of a normal scale to avoid the effect from a large residual error of prediction at a higher concentration zone during the infusion period. The algorithm used for minimization of the SSEs in this study was random heuristic optimization as described elsewhere [16]. This method has good convergence speed and can be conveniently implemented in a spreadsheet.

\subsection{Pharmacodynamic Assessment using Monte Carlo simulation}

The pharmacodynamic assessment of imipenem concentrations in this study was performed using a Monte Carlo simulation (MCS) as described in previous studies [17-19]. A lognormal distribution was used for the PK parameters during the MCS. Covariates that had weak correlations with pharmacokinetic parameters or covariates with only a few extreme values were excluded from the simulation in order to avoid numerical artifacts. Following these exclusions, only creatinine clearance and flow rate of ECMO circuit were used in the study. A Cholesky decomposition matrix of the covariance matrix was created to simulate realistic pharmacokinetic parameters and was validated to ensure equivalence with the actual parameters [20, 21]. The simulation was performed using the Visual Basic language program. A set of pharmacokinetic parameters was simulated from the geometric mean and geometric standard deviation (SD) of each parameter. The algorithm for a normal distribution generator was a Box-Muller transform [22]. The simulated pharmacokinetic parameters were used for solving the twocompartment model with a Runge-Kutta order 4 algorithm for each dosage regimen to achieve the concentration-time profiles [23]. Hence, the exposure time during which the drug concentrations remained above the $T>{ }_{\text {MIC }}$ could be computed from each simulation. The simulations program was written in the Basic language and compiled with Quick Basic compiler version 3 of Microsoft Corporation and run in Microsoft Windows OS. For each MIC simulation, the percentage of $T>{ }_{\text {MIC }}\left(\% T>{ }_{\text {MIC }}\right)$ was computed. We performed 20,000 simulations to obtain $40 \% T>{ }_{\text {MIC }}$ and $80 \%$ $T>_{\text {MIC }}$ in each simulated condition.

\section{Results}

Ten patients were enrolled in the study (six males and four females). Their mean age was $47.20 \pm 13.85$ years (range $18-67$ years), their mean weight was $63.20 \pm 8.66 \mathrm{~kg}$ (range $54-78 \mathrm{~kg}$ ), and their mean body mass index was $24.43 \pm 3.83 \mathrm{~kg} / \mathrm{m}^{2}$ (range $18.04-28.65 \mathrm{~kg} / \mathrm{m}^{2}$ ). The characteristics of all patients are shown in Table 1 . The pharmacokinetic parameters of imipenem are shown in Table 2. Creatinine clearance $\left(\mathrm{CL}_{\mathrm{CR}}\right)$ as estimated by the Cockcroft and Gault equation, total bilirubin, alanine transaminase, the use of adrenaline and/or dopamine and flow rate of the ECMO circuit were significant covariates describing the elimation rate constant $\left(k_{\mathrm{e}}\right)$ of imipenem. The PTAs for various dosage regimens of imipenem for achieving $40 \% T>$ MIC and $80 \% T>{ }_{\text {MIC }}$ in patients with various ranges of $\mathrm{CL}_{\mathrm{CR}}$ and flow rate of ECMO circuit are shown in Tables 3 and 4. The PTAs for different 1-h and 4-h infusions of imipenem 


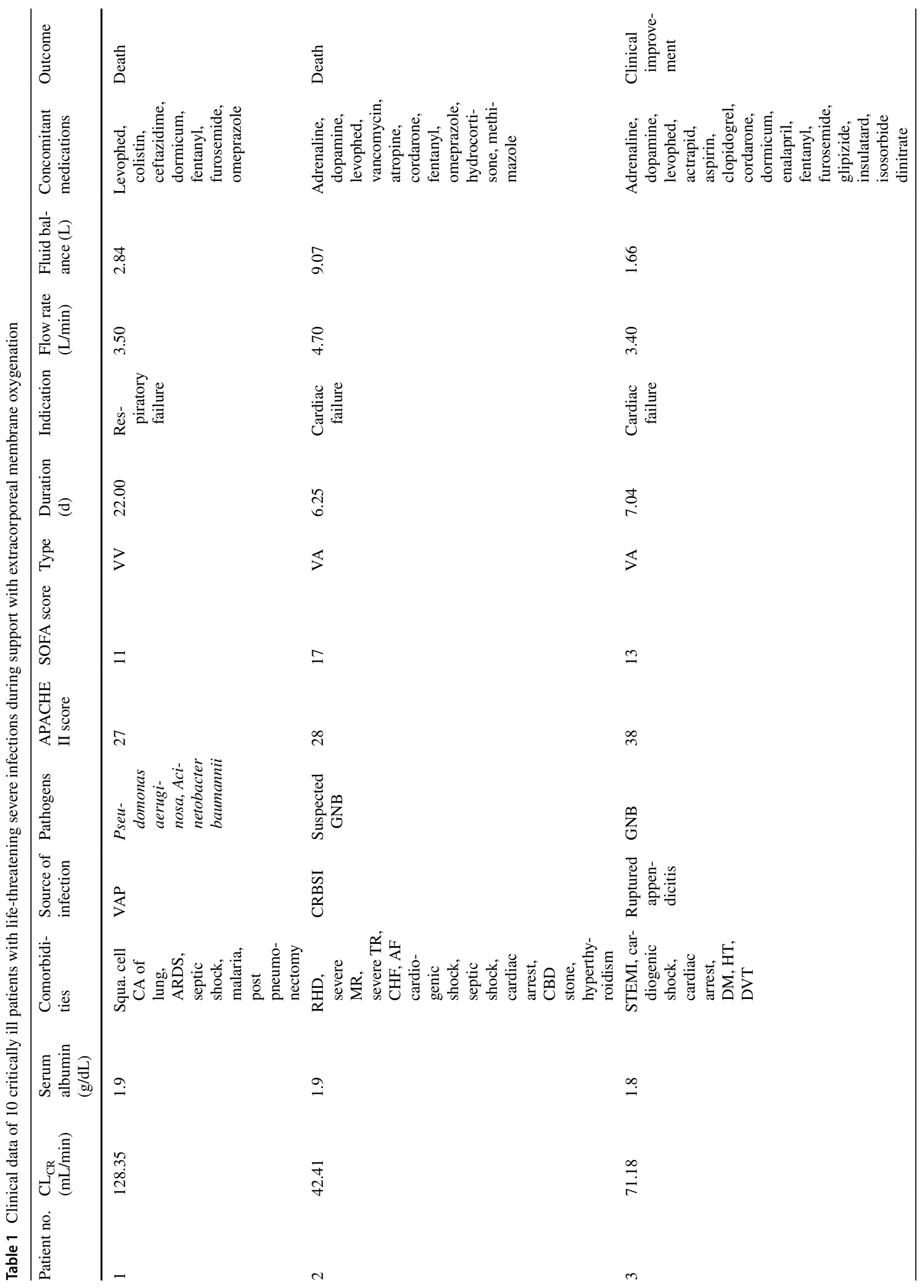




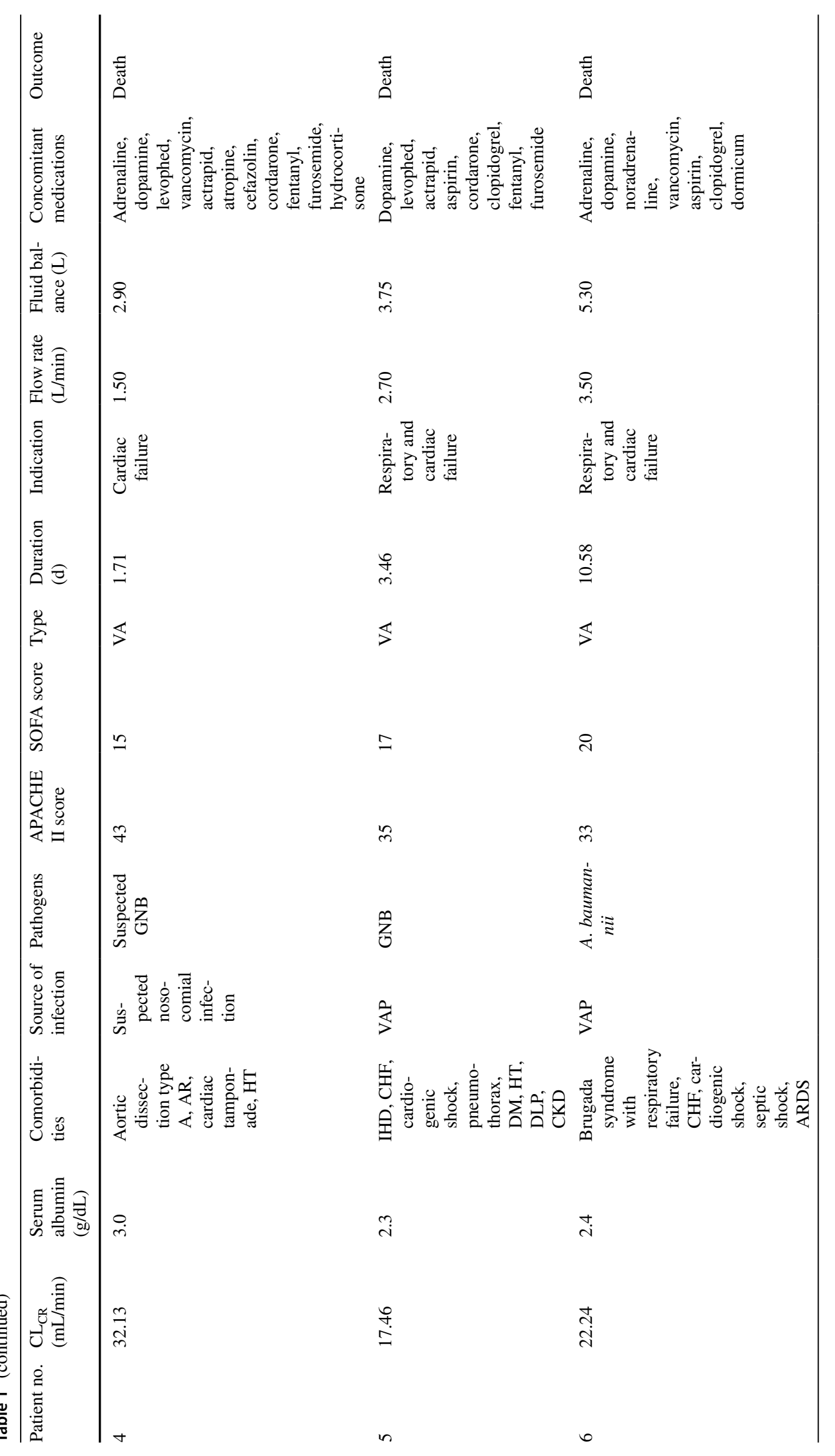




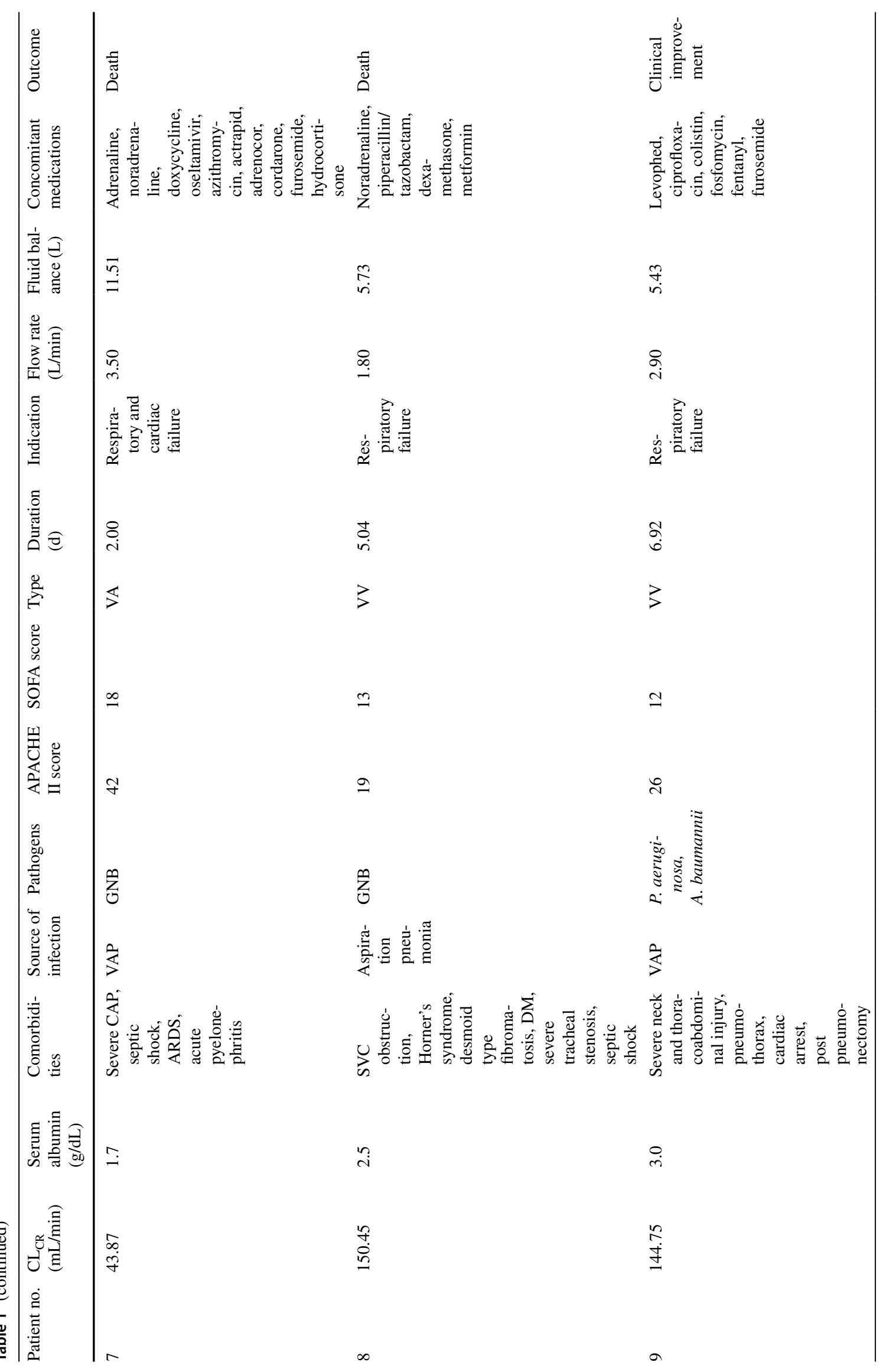




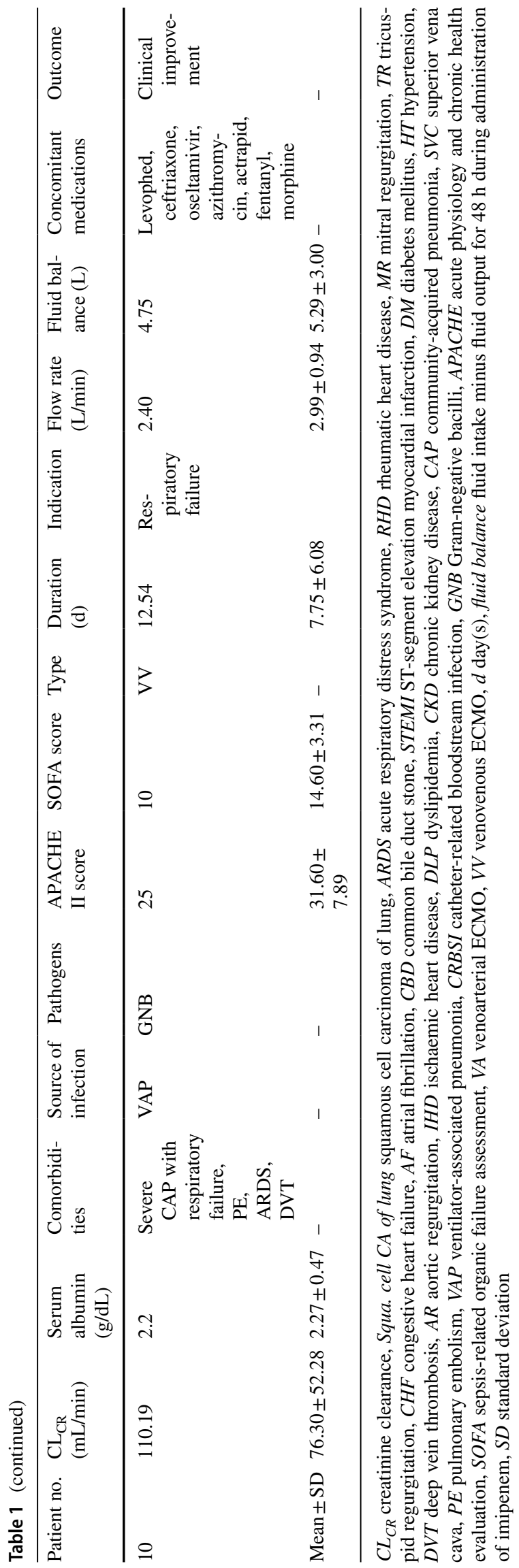

at specific MICs, with targets of $40 \% T>{ }_{\text {MIC }}$ and $80 \%$ $T>{ }_{\text {MIC }}$ in patients with $\mathrm{CL}_{\mathrm{CR}} 15-29.9,30-59.9$ and $60-120 \mathrm{~mL} / \mathrm{min}$ and flow rate of ECMO circuit 1-2.99 and $3-5.5 \mathrm{~L} / \mathrm{min}$ are shown in Fig. 1. The PTAs for achieving $40 \% T>_{\text {MIC }}$ and $80 \% T>_{\text {MIC }}$ of the 4-h infusion regimens were greater than those for the 1 -h infusion regimens.

\section{Discussion}

Sepsis and septic shock in patients with multiple comorbidities cause an alteration of pathophysiological conditions that result in pharmacokinetic changes and subsequently affect therapeutic plasma concentrations and the achievement of pharmacodynamic targets for antimicrobial therapy [24, 25]. Several studies involving patients with seriously ill conditions with life-threatening severe infections during support with ECMO found that the ECMO circuit had an impact on the pharmacokinetic, including $V$ and CL, of antimicrobial agents through several mechanisms [1-3]. First, direct extraction of antimicrobial agents by the ECMO circuit is a well-recognized effect that results in altered pharmacokinetics of the concomitant antibiotics. This effect depends primarily on both the physicochemical properties of the antibiotic and the component materials of the circuit. The molecular weight, degree of ionization, plasma protein binding and lipophilicity of the drugs may also have an influence on the extraction of antimicrobial agents [1]. Ex vivo studies have demonstrated that highly lipophilic and protein-binding antibiotics are prone to increased sequestration when subjected to an ECMO circuit. Moreover, the large surface area of the tubing and membranes of the ECMO circuit can adsorb the amounts of the antimicrobial agents prescribed in patients during support with ECMO, leading to significantly altered pharmacokinetics [1-3]. Second, a large volume of exogenous fluid, including blood, blood products and crystalloid fluid, is required to maintain the circuit flows of ECMO, resulting in increased $V$ of antimicrobial agents due to a hemodilution effect. For antibiotics used in lifethreatening severe infections during support with ECMO, the impact of hemodilution is greater on drugs whose distribution is limited to the central compartment than the agents that are distributed widely to the tissues [1-3]. In addition, pathophysiological changes from life-threatening severe infections in patients who have severe comorbidities result in altered pharmacokinetic patterns for antimicrobial agents. Extravasation of a large volume of fluid resuscitation into extravascular spaces, associated with endothelial damage and subsequently enhanced capillary permeability, causes larger $V$ than the values obtained from healthy volunteers [26-28]. Third, the ECMO circuit has been found to be associated with decreased drug clearance, in addition to those related to end-organ dysfunction due to severe infections 
Table 2 Pharmacokinetic parameters of imipenem in 10 critically ill patients with life-threatening severe infections during support with ECMO following administration of a 1-h infusion of $0.5 \mathrm{~g}$ every $6 \mathrm{~h}$

\begin{tabular}{llllllll}
\hline Patients & $k_{12}(/ \mathrm{h})$ & $k_{21}(/ \mathrm{h})$ & $k_{e}(/ \mathrm{h})$ & $V_{c}(\mathrm{~L})$ & $V_{p}(\mathrm{~L})$ & CL $(\mathrm{L} / \mathrm{h})$ & Sum square error \\
\hline Subject 1 & 0.47 & 0.63 & 0.68 & 25.46 & 19.13 & 17.41 & 0.071 \\
Subject 2 & 0.7 & 0.77 & 0.33 & 32.42 & 29.64 & 10.68 & 0.009 \\
Subject 3 & 16.11 & 13.83 & 0.51 & 24.12 & 28.1 & 12.32 & 0.204 \\
Subject 4 & 1.25 & 0.89 & 0.69 & 17.2 & 24.12 & 11.91 & 0.023 \\
Subject 5 & 2.55 & 1.69 & 0.79 & 11.36 & 17.09 & 8.96 & 0.24 \\
Subject 6 & 3.99 & 1.68 & 0.46 & 11.25 & 26.64 & 5.13 & 0.806 \\
Subject 7 & 6.08 & 2.71 & 0.64 & 10.42 & 23.39 & 6.68 & 0.057 \\
Subject 8 & 2.86 & 2.97 & 1.86 & 17.46 & 16.8 & 32.46 & 0.098 \\
Subject 9 & 4.65 & 2.52 & 1.51 & 4.3 & 7.83 & 6.39 & 0.076 \\
Subject 10 & 2.97 & 1.5 & 2.08 & 2.31 & 4.59 & 4.82 & 0.156 \\
Geometric mean & 2.64 & 1.86 & 0.8 & 12.3 & 17.35 & 9.82 & - \\
Geometric SD & 2.83 & 2.42 & 1.85 & 2.28 & 1.83 & 1.8 & - \\
Median (95\%CI) & $2.92(0.52-12.93)$ & $1.69(0.65-9.78)$ & $0.69(0.35-2.03)$ & 13.98 & 21.15 & $9.78(4.89-28.21)$ & - \\
& & & & $(2.65-$ & $(5.18-$ & \\
\hline
\end{tabular}

$k_{12}$ intercompartment transfer rate constant from compartment $\mathrm{X} 1$ to $\mathrm{X} 2, k_{21}$ intercompartment transfer rate constant from compartment $\mathrm{X} 2$ to $\mathrm{X} 1, k_{e}$ the elimination rate constant, $V_{c}$ central volume of distribution, $V_{p}$ peripheral volume of distribution, $C L$ the total clearances

and septic shock in late-stage disease. However, previous studies examining the impact of this life-support modality were conducted in neonatal populations $[1,2]$, while only a few pharmacokinetic studies carried out in adult populations found that $V$ and CL were not significantly different from values obtained from critically ill patients without ECMO $[1,29,30]$. These findings may be due to significant differences in physiologic processes between these two populations that influence absorption, distribution, metabolism and excretion as well as the small $V$ of the patients compared to the total circulating blood volume of neonates during support with ECMO.

In the current study, the pharmacokinetic studies of imipenem were performed in critically ill patients with lifethreatening severe Gram-negative bacilli infections during support with ECMO, and the two-compartment model was the best model for describing the concentration-time profile of this agent, which was consistent with the results of previous population pharmacokinetic studies [14, 15]. The plasma concentrations of imipenem were highly variable, resulting in high variability of pharmacokinetic parameters. The results of the current study may be due to differences in both pathophysiological conditions of comorbidities and the amount of fluid resuscitation as well as the use of inotropic drugs for the management of severe infections, including septic shock. The median value of $V$ was $30.3 \mathrm{~L}$, which was consistent with the values obtained from critically ill patients without ECMO support in another study [7]. A possible explanation for the high $V$ in the current study is that the study was conducted in very critically ill patients with life-threatening severe infections who had respiratory and/or cardiac failure, resulting in requiring support with ECMO. All recruited patients had APACHE II scores of $\geq 19$ and SOFA scores of $\geq 10$ and half of them had septic shock. However, imipenem is a hydrophilic antibiotic with low protein binding $(<10$ to $20 \%$ ) which results in a low degree of extraction by the ECMO circuit when compared to highly lipophilic agents with high protein-binding antimicrobial agents. The median value of CL from the current study was $9.78 \mathrm{~L} / \mathrm{h}$, which was $>2$-fold lower than the value obtained from critically ill patients without ECMO support [15]. A possible explanation for this finding is that the enrolled patients had life-threatening severe infections and half of them had septic shock causing decreased renal perfusion leading to the development of end organ dysfunction. Moreover, at enrollment, one-half of the patients were experiencing renal dysfunction, as defined by $\mathrm{CL}_{\mathrm{CR}}$ values of $\leq 60 \mathrm{~mL} / \mathrm{min}$.

Previous studies in animal models have shown that, for $\beta$-lactam antibiotics, it is not necessary for plasma drug concentrations to be above the MIC for $100 \%$ of the dosing interval to achieve significant antimicrobial effects [24, 25]. One study reported that in a murine thigh infection model, bactericidal effects of carbapenem were observed when serum drug concentrations were above the MIC for $40 \%$ of the dosing interval in order to achieve a significant antimicrobial effect [31]. However, for life-threatening severe infections, particularly in immunocompromised hosts, the $T$ 
Table 3 Probability of target attainment (PTA) for imipenem regimens achieving $40 \% T>$ MIC and $80 \% T>_{\text {MIC }}$ at various creatinine clearance $(\mathrm{mL} / \mathrm{min})$ levels $\left(\mathrm{CL}_{\mathrm{CR}}\right)$ in 10 critically ill patients with life-threatening severe infections during support with extracorporeal membrane oxygenation (flow rate 3-5.5 L/min). MIC minimum inhibitory concentration, $q x h$ every $x$ hours

\begin{tabular}{|c|c|c|c|c|c|c|c|c|}
\hline \multirow[t]{3}{*}{ Dosage regimen } & \multirow{3}{*}{$\begin{array}{l}\text { Duration of } \\
\text { infusion (h) }\end{array}$} & \multirow[t]{3}{*}{$\mathrm{MIC}(\mu \mathrm{g} / \mathrm{mL})$} & \multicolumn{6}{|c|}{ Probability of attaining the following $\% T>_{\text {MIC }}$} \\
\hline & & & \multicolumn{2}{|c|}{$\mathrm{CL}_{\mathrm{CR}} 15-29.9$} & \multicolumn{2}{|c|}{$\mathrm{CL}_{\mathrm{CR}} 30-59.9$} & \multicolumn{2}{|c|}{$\mathrm{CL}_{\mathrm{CR}} 60-120$} \\
\hline & & & $40 \%$ & $80 \%$ & $40 \%$ & $80 \%$ & $40 \%$ & $80 \%$ \\
\hline \multirow[t]{8}{*}{$0.5 \mathrm{~g} \mathrm{q} 6 \mathrm{~h}$} & \multirow[t]{4}{*}{1} & 1 & 100 & 99.99 & 100 & 99.99 & 100 & 99.68 \\
\hline & & 2 & 99.91 & 99.31 & 99.88 & 98.57 & 99.76 & 94.09 \\
\hline & & 4 & 96.83 & 87.45 & 95.76 & 82.22 & 92.94 & 63.82 \\
\hline & & 8 & 71.05 & 43.93 & 66.29 & 36.81 & 56.19 & 19.75 \\
\hline & \multirow[t]{4}{*}{4} & 1 & 100 & 99.99 & 100 & 99.99 & 100 & 99.97 \\
\hline & & 2 & 99.93 & 99.44 & 99.82 & 99.32 & 99.7 & 98.56 \\
\hline & & 4 & 96.59 & 89.41 & 95.52 & 87.61 & 93.09 & 80.53 \\
\hline & & 8 & 70.54 & 48.99 & 66.32 & 44.92 & 57.96 & 33.51 \\
\hline \multirow[t]{9}{*}{$1 \mathrm{~g} \mathrm{q} 8 \mathrm{~h}$} & \multirow[t]{4}{*}{1} & 1 & 100 & 100 & 100 & 100 & 100 & 99.79 \\
\hline & & 2 & 100 & 99.89 & 100 & 99.64 & 99.99 & 96.12 \\
\hline & & 4 & 99.59 & 96.06 & 99.32 & 92.41 & 98.51 & 74.84 \\
\hline & & 8 & 90.65 & 67.94 & 87.79 & 57.1 & 80.15 & 31.39 \\
\hline & \multirow[t]{5}{*}{4} & 1 & 100 & 99.99 & 100 & 100 & 100 & 99.99 \\
\hline & & 2 & 100 & 99.9 & 99.98 & 99.85 & 99.96 & 99.13 \\
\hline & & 4 & 99.47 & 97.19 & 99.3 & 95.72 & 98.73 & 88.28 \\
\hline & & 8 & 90.3 & 72.91 & 88.34 & 67.42 & 83.91 & 48.74 \\
\hline & & 16 & 50.31 & 25.13 & 46.52 & 19.92 & 39.17 & 10.46 \\
\hline \multirow[t]{10}{*}{$1 \mathrm{~g} \mathrm{q} 6 \mathrm{~h}$} & \multirow[t]{5}{*}{1} & 1 & 100 & 100 & 100 & 100 & 100 & 99.99 \\
\hline & & 2 & 100 & 99.99 & 100 & 99.98 & 100 & 99.7 \\
\hline & & 4 & 99.92 & 99.36 & 99.88 & 98.64 & 99.75 & 94.17 \\
\hline & & 8 & 96.91 & 87.24 & 95.85 & 82.5 & 92.89 & 63.75 \\
\hline & & 16 & 70.85 & 44.28 & 66.53 & 36.23 & 56.21 & 19.61 \\
\hline & \multirow[t]{5}{*}{4} & 1 & 100 & 100 & 100 & 100 & 100 & 100 \\
\hline & & 2 & 100 & 99.97 & 100 & 99.98 & 100 & 99.99 \\
\hline & & 4 & 99.91 & 99.46 & 99.84 & 99.28 & 99.71 & 98.45 \\
\hline & & 8 & 96.86 & 89.73 & 95.43 & 87.8 & 93.16 & 80.18 \\
\hline & & 16 & 70.42 & 48.54 & 66.38 & 45.24 & 57.87 & 33.19 \\
\hline \multirow[t]{4}{*}{$2 \mathrm{~g} \mathrm{q} 24 \mathrm{~h}$} & \multirow[t]{4}{*}{24} & 1 & 99.99 & 99.97 & 100 & 99.98 & 99.99 & 99.97 \\
\hline & & 2 & 99.69 & 98.97 & 99.53 & 98.88 & 99.08 & 98.52 \\
\hline & & 4 & 93 & 86.15 & 90.88 & 85.61 & 85.78 & 81 \\
\hline & & 8 & 57.9 & 43.74 & 51.92 & 41.84 & 41.95 & 34.58 \\
\hline \multirow[t]{4}{*}{$3 \mathrm{~g} \mathrm{q} 24 \mathrm{~h}$} & \multirow[t]{4}{*}{24} & 1 & 100 & 100 & 100 & 100 & 99.99 & 99.99 \\
\hline & & 2 & 99.98 & 99.85 & 99.96 & 99.85 & 99.89 & 99.81 \\
\hline & & 4 & 98.77 & 96.34 & 98.14 & 96.41 & 96.62 & 94.87 \\
\hline & & 8 & 82.67 & 71.39 & 79.85 & 71.52 & 70.75 & 63.57 \\
\hline \multirow[t]{4}{*}{$4 \mathrm{~g} \mathrm{q} 24 \mathrm{~h}$} & \multirow[t]{4}{*}{24} & 1 & 100 & 100 & 100 & 100 & 100 & 100 \\
\hline & & 2 & 100 & 99.95 & 100 & 99.99 & 99.99 & 99.98 \\
\hline & & 4 & 99.68 & 98.98 & 99.65 & 99.07 & 98.97 & 98.41 \\
\hline & & 8 & 93.03 & 86.05 & 91.14 & 85.85 & 85.78 & 81.04 \\
\hline
\end{tabular}

$>$ MIC required for the optimal antimicrobial activity should be close to $100 \%$ of the dosing interval. A previous clinical study in immunocompromised patients with febrile neutropenia found that the optimal clinical response of meropenem for the treatment of bacteremia was achieved when the percentages of $T>_{\text {MIC }}$ of meropenem were $>75 \%$ of the dosing interval [32]. Therefore, in the current study we performed a Monte Carlo dosing simulation to determine the probability of attaining targets of $80 \% T>{ }_{\text {MIC }}$ using various dosing regimens, renal functions and flow rates of the ECMO circuit for the treatment of life-threatening severe infections in critically ill patients during support with ECMO. High 
Table 4 Probability of target attainment (PTA) for imipenem regimens achieving $40 \%$

$T>_{\text {MIC }}$ and $80 \% T>$ MIC at various creatinine clearance $(\mathrm{mL} / \mathrm{min})$ levels $\left(\mathrm{CL}_{\mathrm{CR}}\right)$ in 10 critically ill patients with life-threatening severe infections during support with extracorporeal membrane oxygenation (flow rate $1-2.99$ $\mathrm{L} / \mathrm{min}$ ). MIC minimum inhibitory concentration, $q x h$ every $x$ hours

\begin{tabular}{|c|c|c|c|c|c|c|c|c|}
\hline \multirow[t]{3}{*}{ Dosage regimen } & \multirow{3}{*}{$\begin{array}{l}\text { Duration of } \\
\text { infusion (h) }\end{array}$} & \multirow[t]{3}{*}{$\mathrm{MIC}(\mu \mathrm{g} / \mathrm{mL})$} & \multicolumn{6}{|c|}{ Probability of attaining the following $\% T>_{\text {MIC }}$} \\
\hline & & & \multicolumn{2}{|c|}{$\mathrm{CL}_{\mathrm{CR}} 15-29.9$} & \multicolumn{2}{|c|}{$\mathrm{CL}_{\mathrm{CR}} 30-59.9$} & \multicolumn{2}{|c|}{$\mathrm{CL}_{\mathrm{CR}} 60-120$} \\
\hline & & & $40 \%$ & $80 \%$ & $40 \%$ & $80 \%$ & $40 \%$ & $80 \%$ \\
\hline \multirow[t]{8}{*}{$0.5 \mathrm{~g} \mathrm{q} 6 \mathrm{~h}$} & \multirow[t]{4}{*}{1} & 1 & 100 & 99.83 & 99.99 & 99.29 & 99.98 & 91.33 \\
\hline & & 2 & 99.81 & 95.44 & 99.69 & 90.12 & 98.55 & 63.18 \\
\hline & & 4 & 94.11 & 67.42 & 91.82 & 53.53 & 82.31 & 23.12 \\
\hline & & 8 & 59.8 & 21.5 & 53.02 & 13.13 & 37.56 & 3.23 \\
\hline & \multirow[t]{4}{*}{4} & 1 & 100 & 99.98 & 100 & 99.97 & 99.98 & 99.72 \\
\hline & & 2 & 99.78 & 98.9 & 99.75 & 98.2 & 99.45 & 93.32 \\
\hline & & 4 & 94.87 & 83.84 & 93.38 & 77.67 & 90.23 & 59.72 \\
\hline & & 8 & 63.28 & 37.73 & 58.95 & 30.15 & 50.87 & 15.84 \\
\hline \multirow[t]{9}{*}{$1 \mathrm{~g} \mathrm{q} 8 \mathrm{~h}$} & \multirow[t]{5}{*}{1} & 0.5 & 100 & 100 & 100 & 99.99 & 100 & 97.18 \\
\hline & & 1 & 100 & 99.92 & 100 & 99.36 & 99.99 & 87.87 \\
\hline & & 2 & 99.98 & 97.51 & 99.98 & 92.57 & 99.4 & 61.36 \\
\hline & & 4 & 98.82 & 78.48 & 97.9 & 63.01 & 91.94 & 25.5 \\
\hline & & 8 & 82.85 & 34.55 & 77.35 & 20.72 & 58.48 & 4.86 \\
\hline & \multirow[t]{4}{*}{4} & 1 & 100 & 100 & 100 & 99.97 & 100 & 99.11 \\
\hline & & 2 & 99.99 & 99.55 & 99.96 & 98.62 & 99.98 & 90.82 \\
\hline & & 4 & 99.33 & 90.84 & 98.98 & 83.96 & 98.47 & 58.9 \\
\hline & & 8 & 87.47 & 53.15 & 85.09 & 41.26 & 81.79 & 18.42 \\
\hline \multirow[t]{8}{*}{$1 \mathrm{~g} \mathrm{q} 6 \mathrm{~h}$} & \multirow[t]{4}{*}{1} & 1 & 100 & 100 & 100 & 99.98 & 100 & 98.91 \\
\hline & & 2 & 100 & 99.87 & 100 & 99.33 & 99.99 & 90.75 \\
\hline & & 4 & 99.85 & 95.37 & 99.74 & 89.93 & 98.55 & 63.31 \\
\hline & & 8 & 94.11 & 67.65 & 91.7 & 53.64 & 82.75 & 23.2 \\
\hline & \multirow[t]{4}{*}{4} & 1 & 100 & 100 & 100 & 99.99 & 100 & 100 \\
\hline & & 2 & 100 & 99.99 & 99.99 & 99.99 & 99.99 & 99.71 \\
\hline & & 4 & 99.8 & 98.94 & 99.77 & 98.14 & 99.47 & 93.04 \\
\hline & & 8 & 94.8 & 83.47 & 93.38 & 77.19 & 89.93 & 60.05 \\
\hline \multirow[t]{3}{*}{$2 \mathrm{~g} \mathrm{q} 24 \mathrm{~h}$} & \multirow[t]{3}{*}{24} & 1 & 100 & 99.99 & 99.98 & 99.96 & 99.96 & 99.9 \\
\hline & & 2 & 99.45 & 99 & 99.08 & 98.48 & 98.13 & 96.68 \\
\hline & & 4 & 88.69 & 84.79 & 86.14 & 81.17 & 78.43 & 71.02 \\
\hline \multirow[t]{4}{*}{$3 \mathrm{~g} \mathrm{q} 24 \mathrm{~h}$} & \multirow[t]{4}{*}{24} & 1 & 100 & 100 & 100 & 100 & 100 & 100 \\
\hline & & 2 & 99.93 & 99.91 & 99.93 & 99.87 & 99.72 & 99.48 \\
\hline & & 4 & 97.76 & 96.4 & 96.63 & 94.96 & 93.72 & 90.38 \\
\hline & & 8 & 75.58 & 69.17 & 70.82 & 63.77 & 60.13 & 51.24 \\
\hline \multirow[t]{4}{*}{$4 \mathrm{~g} \mathrm{q} 24 \mathrm{~h}$} & \multirow[t]{4}{*}{24} & 1 & 100 & 100 & 100 & 100 & 100 & 100 \\
\hline & & 2 & 99.99 & 99.98 & 99.98 & 99.98 & 99.93 & 99.87 \\
\hline & & 4 & 99.4 & 98.96 & 99.13 & 98.47 & 98.08 & 96.77 \\
\hline & & 8 & 89.09 & 84.86 & 85.65 & 80.51 & 78.33 & 71.1 \\
\hline
\end{tabular}

PTAs $(\geq 90 \%)$ achieving $80 \% T>{ }_{\text {MIC }}$ in patients with $\mathrm{CL}_{\mathrm{CR}}$ $60-120 \mathrm{~mL} / \mathrm{min}$ and flow rate $3-5.5 \mathrm{~L} / \mathrm{min}$ for a MIC of $2 \mu \mathrm{g} / \mathrm{mL}$ were observed when imipenem was administered by a 4-h infusion of $0.5 \mathrm{~g}$ every $6 \mathrm{~h}, 1 \mathrm{~g}$ every $8 \mathrm{~h}$ and $1 \mathrm{~g}$ every $6 \mathrm{~h}$. For pathogens with a MIC of $4 \mu \mathrm{g} / \mathrm{mL}$, high PTAs were achieved only when the dosages of imipenem were administered by a 4-h infusion of $1 \mathrm{~g}$ every $6 \mathrm{~h}$. The findings of the current study indicate that high dosage regimens of imipenem are required for coverage of less susceptible pathogens for achieving the maximal pharmacodynamic targets and therapeutic outcomes in this patient population. We examined the probabilities of dosage regimens of imipenem achieving targets of $80 \% T>{ }_{\text {MIC }}$ at various ranges of $\mathrm{CL}_{\mathrm{CR}}$ (15-29.9, 30-59.9, and 60-120 mL/min) and found that the achievement of the pharmacodynamic targets of imipenem at $\mathrm{CL}_{\mathrm{CR}}$ 15-29.9 $\mathrm{mL} / \mathrm{min}$ was superior to those of $\mathrm{CL}_{\mathrm{CR}}$ 30-59.9 and 60-120 $\mathrm{mL} / \mathrm{min}$ and the achievement of the pharmacodynamic targets at $\mathrm{CL}_{\mathrm{CR}}$ 30-59.9 was superior 
a ECMO flow rate $3-5.5 \mathrm{~L} / \mathrm{min}, \mathrm{CL}_{\mathrm{CR}} 60-120 \mathrm{~mL} / \mathrm{min}, 40 \% \mathrm{PTA}$

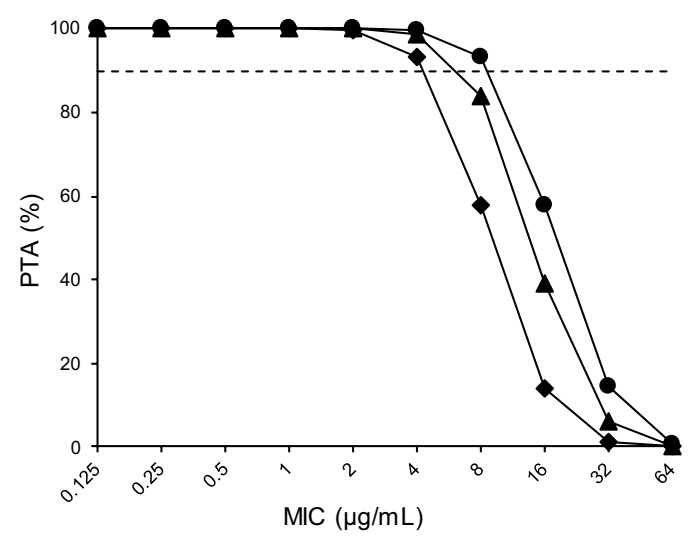

C ECMO flow rate $1-2.99 \mathrm{~L} / \mathrm{min}, \mathrm{CL}_{\mathrm{CR}} 60-120 \mathrm{~mL} / \mathrm{min}, 40 \% \mathrm{PTA}$

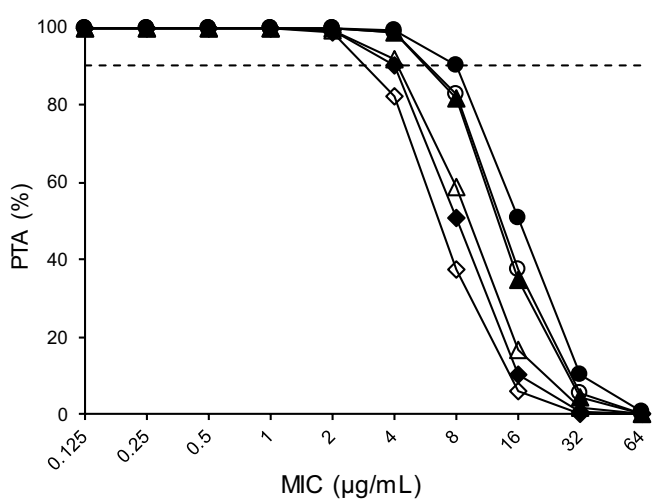

Fig. 1 Probability of target attainment (PTA) for imipenem regimens achieving (a) $40 \% T>_{\text {MIC }}$ at flow rate $3-5.5 \mathrm{~L} / \mathrm{min}$, with $\mathrm{CL}_{\mathrm{CR}}$ 60-120 mL/min, (b) $80 \% \mathrm{~T}>$ MIC at flow rate $3-5.5 \mathrm{~L} / \mathrm{min}$, with $\mathrm{CL}_{\mathrm{CR}} 60-120 \mathrm{~mL} / \mathrm{min}$, (c) $40 \% \mathrm{~T}>{ }_{\mathrm{MIC}}$ at flow rate $1-2.99 \mathrm{~L} / \mathrm{min}$, with $\mathrm{CL}_{\mathrm{CR}} 60-120 \mathrm{~mL} / \mathrm{min}$ and (d) $80 \% T>{ }_{\text {MIC }}$ at flow rate $1-2.99$ $\mathrm{L} / \mathrm{min}$, with $\mathrm{CL}_{\mathrm{CR}} 60-120 \mathrm{~mL} / \mathrm{min}$ at specific minimum inhibitory concentrations (MICs) in 10 critically ill patients with life-threatening

to those of $\mathrm{CL}_{\mathrm{CR}} 60-120 \mathrm{~mL} / \mathrm{min}$ at the same daily dosage. Therefore, in critically ill patients with life-threatening severe infections during support with ECMO, the dosage regimens are not as high as those required in patients with normal renal function. We also examined the probabilities of dosage regimens of imipenem achieving targets of $80 \%$ $T>_{\text {MIC }}$ at various ranges of flow rates of the ECMO circuit $(1-2.99 \mathrm{~L} / \mathrm{min}$ and $3-5.5 \mathrm{~L} / \mathrm{min})$ and found that the achievement of pharmacodynamic targets of imipenem at a high flow rate of 3-5.5 $\mathrm{L} / \mathrm{min}$ was superior to those achieved at a low flow rate of $1-2.99 \mathrm{~L} / \mathrm{min}$ at the same daily dosage. The explanation for this finding is that increased contact time between imipenem and the large adsorption surface of the ECMO circuit during the low flow rate had more impact on drug adsorption than during the high flow rate. However, for achieving the high PTAs $(\geq 90 \%)$ at the high flow rate b ECMO flow rate 3-5.5 L/min, $\mathrm{CL}_{\mathrm{CR}} 60-120 \mathrm{~mL} / \mathrm{min}, 80 \% \mathrm{PTA}$

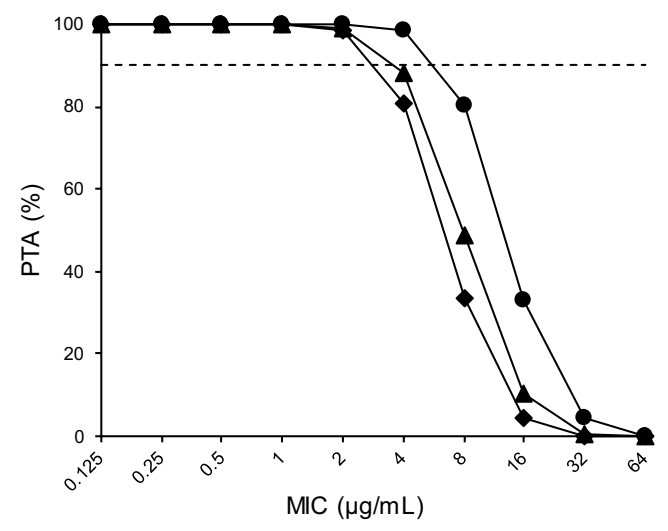

d ECMO flow rate $1-2.99 \mathrm{~L} / \mathrm{min}, \mathrm{CL}_{\mathrm{CR}} 60-120 \mathrm{~mL} / \mathrm{min}, 80 \% \mathrm{PTA}$

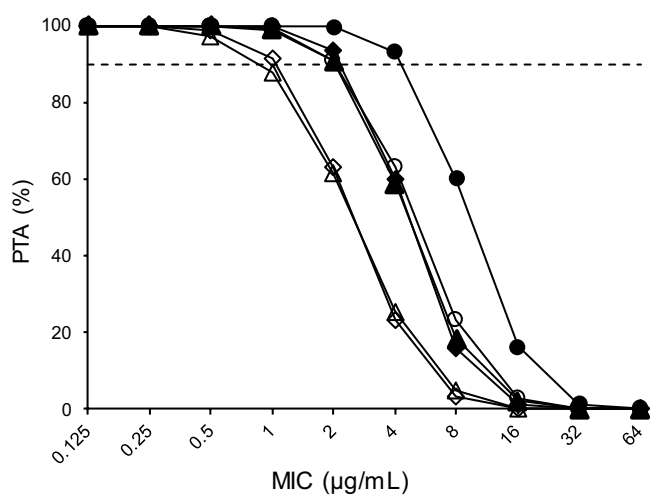

severe infections during support with ECMO after administration of a 1-h infusion of $0.5 \mathrm{~g}$ every $6 \mathrm{~h}$ (open diamond), a 4-h infusion of $0.5 \mathrm{~g}$ every $6 \mathrm{~h}$ (close diamond), a 1 -h infusion of $1 \mathrm{~g}$ every $8 \mathrm{~h}$ (open triangle), a 4-h infusion of $1 \mathrm{~g}$ every $8 \mathrm{~h}$ (close triangle), a 1-h infusion of $1 \mathrm{~g}$ every $6 \mathrm{~h}$ (open circle), a 4-h infusion of $1 \mathrm{~g}$ every $6 \mathrm{~h}$ (close circle). The broken line represents 90\% PTA. $T>_{\text {MIC }}$, time that concentrations in tissue and serum were above the MIC

3-5.5 L/min and at the low flow rate $1-2.99 \mathrm{~L} / \mathrm{min}$, the same dosage regimens could be used. In both the European Committee on Antimicrobial Susceptibility Testing (EUCAST) and the Clinical Laboratory Standards Institute (CLSI), the MIC breakpoints for Pseudomonas aeruginosa are $4 \mu \mathrm{g} / \mathrm{mL}$. Therefore, the highest licensed dosage regimen ( $1 \mathrm{~g}$ every $6 \mathrm{~h}$ ) of imipenem should be used against the less susceptible pathogens in this patient population.

The study had a limitation that must be noted, namely the small number of patients. In the absence of data from a larger sample size, however, a MCS based on a small number of patients such as in this study can be instructive in illuminating the effects of different dosing approaches. 


\section{Conclusion}

Pathophysiological changes in critical illness in patients receiving ECMO resulted in altered pharmacokinetic patterns of imipenem. The highest licensed dosage regimen, $1 \mathrm{~g}$ every $6 \mathrm{~h}$, of imipenem was required to achieve the pharmacodynamic targets for optimal therapeutic outcome against the less susceptible pathogens in this patient population. Further large well-defined clinical trials with controlled data from a patient population not receiving ECMO are required to confirm these findings.

Acknowledgements The authors thank Mr David Patterson of the International Affairs Office of the Faculty of Medicine, Prince of Songkla University for English proofreading of the manuscript.

Author contributions In this article, SJ participated in conducting the clinical trial and writing of the paper. VV participated in conducting the clinical trial. WW and MN participated in data analysis. MS participated in collecting the information of the paper. All authors read and approved the final manuscript. The authors confirm that the principal investigator for this paper was SJ.

\section{Declarations}

Funding This work was supported by a grant from the Faculty of Medicine, Prince of Songkla University.

Conflicts of interest Sutep Jaruratanasirikul, Veerapong Vattanavanit, Wibul Wongpoowarak, Monchana Nawakitrangsan and Maseetoh Samaeng have no conflicts of interest that are relevant to the content of this paper.

Ethical approval All procedures performed in studies involving human participants were in accordance with the study protocol, the Ministerial Ordinance on GCP for Drugs, and with the 1964 Helsinki Declaration and its later amendments or comparable ethical standards. The study protocol (code EC-56-065-14-1-1) was approved by the IRB at Songklanagarind Hospital on 17 December 2012.

Consent to participate Informed consent was obtained from each subject's legally acceptable representative before enrollment.

Consent for publication The authors have consent from their institutions.

Code availability Available at: https://drive.google.com/file/d/13mmg V89HHe48rUqctbVthBqizYlYP1Px/view?usp=sharing.

\section{References}

1. Sherwin J, Heath T, Watt K. Pharmacokinetics and dosing of anti-infective drugs in patients on extracorporeal membrane oxygenation: a review of the current literature. Clin Ther. 2016;38(9):1976-94.

2. Honoré PM, Jacobs R, Spapen HD. Antimicrobial dosing during extracorporeal membrane oxygenation. In: Vincent JL, editor. Annual update in intensive care and emergency medicine. New York: Springer; 2014. p. 43-52.
3. Shekar K, Fraser JF, Smith MT, Roberts JA. Pharmacokinetic changes in patients receiving extracorporeal membrane oxygenation. J Crit Care. 2012;27(6):741.e9-18.

4. Hahn J, Choi JH, Chang MJ. Pharmacokinetic changes of antibiotic, antiviral, antituberculosis and antifungal agents during extracorporeal membrane oxygenation in critically ill adult patients. J Clin Pharm Ther. 2017;42(6):661-71.

5. Rodloff AC, Goldstein EJC, Torres A. Two decades of imipenem therapy. J Antimicrob Chemother. 2006;58(5):916-29.

6. Balfour JA, Bryson HM, Brogden RN. Imipenem/Cilastatin: an update of its antibacterial activity, pharmacokinetics and therapeutic efficacy in the treatment of serious infections. Drugs. 1996;51(1):99-136.

7. Couffignal C, Pajot O, Laouénan C, Burdet C, Foucrier A, Wolff $\mathrm{M}$, et al. Population pharmacokinetics of imipenem in critically ill patients with suspected ventilator-associated pneumonia and evaluation of dosage regimens. Br J Clin Pharmacol. 2014;78(5):1022-34.

8. Jaruratanasirikul S, Raungsri N, Punyo J, Sriwiriyajan S. Pharmacokinetics of imipenem in healthy volunteers following administration by $2 \mathrm{~h}$ or $0.5 \mathrm{~h}$ infusion. $\mathrm{J}$ Antimicrob Chemother. 2005;56(6):1163-5.

9. Viaene E, Chanteux H, Servais H, Mingeot-Leclercq MP, Tulkens PM. Comparative stability studies of antipseudomonal betalactams for potential administration through portable elastomeric pumps (home therapy for cystic fibrosis patients) and motor-operated syringes (intensive care units). Antimicrob Agents Chemother. 2002;46(8):2327-32.

10. Garcia-Capdevila L, López-Calull C, Arroyo C, Moral MA, Mangues MA, Bonal J. Determination of imipenem in plasma by highperformance liquid chromatography for pharmacokinetic studies in patients. J Chromatogr B. 1997;692(1):127-32.

11. FDA. US Department of Health and Human Services. In: Draft guidance for industry: bioanalytical method validation. 2013. https ://www.fda.gov/downloads/Drugs/GuidanceComplianceRegulat oryInformation/Guidance/UCM368107.pdf. Accessed 21 Jan 2013.

12. Coufignall C, Pajot O, Laouénan C, Burdet C, Foucrier A, Wolff M, Armand-Lefevre L, Mentré F, Massias L. Population pharmacokinetics of imipenem in critically ill patients with suspected ventilator-associated pneumonia and evaluation of dosage regimens. Br J Clin Pharmacol. 2014;78(5):1022-34.

13. Velde F, Winter BCM, Neely MN, Yamada WM, Koch BCP, Harbarth S, Dach E, Gelder T, Huttner A, Mouton JW. Population pharmacokinetics of imipenem in critically ill patients: a parametric and nonparametric model converge on CKD-EPI estimated glomerular filtration rate as an impactful covariate. Clin Pharmacokinet. 2020;59(7):885-98.

14. Jaruratanasirikul S, Wongpoowarak W, Nawakitrangson M, Thengyai S, Samaeng M. Population pharmacokinetics and Monte Carlo dosing simulations of imipenem in patients with ventilatorassociated pneumonia. Lung Breath J. 2017;1(1):1-4.

15. Jaruratanasirikul S, Wongpoowarak W, Jullangkoon M, Samaeng M. Population pharmacokinetics and dosing simulations of imipenem in serious bacteraemia in immunocompromised patients with febrile neutropenia. J Pharmacol Sci. 2015;127(2):164-9.

16. Li J, Rhinehart RR. Heuristic random optimization. Comput Chem Eng. 1998;22(3):427-44.

17. Jaruratanasirikul S, Limapichat T, Jullangkoon M, Aeinlang N, Ingviya $\mathrm{N}$, Wongpoowarak W. Pharmacodynamics of meropenem in critically ill patients with febrile neutropenia and bacteraemia. Int J Antimicrob Agents. 2011;38(3):231-6.

18. Jaruratanasirikul S, Wongpoowarak W, Kositpantawong N, Aeinlang N, Jullangkoon M. Pharmacodynamics of doripenem in critically ill patients with ventilator-associated Gram-negative bacilli pneumonia. Int J Antimicrob Agents. 2012;40(5):434-9. 
19. Jaruratanasirikul S, Wongpoowarak W, Aeinlang N, Jullangkoon A. Pharmacodynamics modeling to optimize dosage regimens of sulbactam. Antimicrob Agents Chemother. 2013;57(7):3441-4.

20. Mouton JW, Ambrose PG, Kahlmeter G, Wikler M. Applying pharmacodynamics for susceptibility breakpoint selection and susceptibility testing. In: Nightingale $\mathrm{CH}$, Ambrose PG, Drusano GL, Murakawa T, editors. Antimicrobial Pharmacodynamics in Theory and Clinical Practice. New York: Informa Healthcare; 2007. p. 21-44.

21. Chang M. Monte Carlo Simulation for the pharmaceutical industry: concepts, algorithms and case studies. Florida: CRC Press; 2011.

22. Box GEP, Muller ME. A note on the generation of random normal deviates. Ann Math Stat. 1958;29(2):610-1.

23. Mathews JH. Numerical methods for computer science, engineering and mathematics. London: Prentice-Hall International; 1987.

24. Taccone FS, Laterre PF, Dugernier T, Spapen H, Delattre I, Wittebole $\mathrm{X}$, et al. Insufficient $\beta$-lactam concentrations in the early phase of severe sepsis and septic shock. Crit Care. 2010;14:R126.

25. Udy AA, Varghese JM, Altukroni M, Briscoe S, McWhinney BC, Ungerer JP, et al. Subtherapeutic initial $\beta$-lactam concentrations in select critically ill patients: association between augmented renal clearance and low trough drug concentrations. Chest. 2012;142(1):30-9.

26. Munford RS, Suffredini AF. Sepsis, severe sepsis, and septic shock. In: Mandell GL, Bennett JE, Dolin R, editors. Mandell,
Douglas, and Bennett's principles and practice of infectious diseases. 7th ed. Philadelphia: Churchill Livingstone Elsevier; 2010. p. 987-1010.

27. Taccone FS, Hites M, Beumier M, Scolletta S, Jacobs F. Appropriate antibiotic dosage levels in the treatment of severe sepsis and septic shock. Curr Infect Dis Rep. 2011;13(5):406-15.

28. Varghese JM, Roberts JA, Lipman J. Antimicrobial pharmacokinetic and pharmacodynamic issues in the critically ill with severe sepsis and septic shock. Crit Care Clin. 2011;27(1):19-34.

29. Donadello K, Antonucci E, Cristallini S, Roberts JA, Beumier $\mathrm{M}$, Scolletta $\mathrm{S}$, et al. $\beta$-Lactam pharmacokinetics during extracorporeal membrane oxygenation therapy: a case-control study. Int J Antimicrob Agents. 2015;45(3):278-82.

30. Shekar K, Fraser JF, Taccone FS, Welch S, Wallis SC, Mullany $\mathrm{DV}$, et al. The combined effects of extracorporeal membrane oxygenation and renal replacement therapy on meropenem pharmacokinetics: a matched cohort study. Crit Care. 2014;18(6):565.

31. Drusano GL. Prevention of resistance: a goal for dose selection for antimicrobial agents. Clin Infect Dis. 2003;36(Suppl 1):S42-50.

32. Ariano RE, Nyhlén A, Donnelly JP, Sitar DS, Harding GKM, Zelenitsky SA. Pharmacokinetics and pharmacodynamics of meropenem in febrile neutropenic patients with bacteremia. Ann Pharmacother. 2005;39(1):32-8. 